\title{
A Review of FACS: Fluorescence Activated Cell Sorting System
}

\author{
Aishwarya Agarwall ${ }^{1}$, Deepak Khushalani ${ }^{2}$, Ankita Harkare ${ }^{3}$ and Rakshal Agrawal ${ }^{4}$ \\ ${ }^{1}$ Research Intern, Shri Ramdeobaba College of Engineering and Management, \\ Nagpur, India, Department of Electronics and Communication Engineering \\ ${ }^{2}$ Assistant Professor, Shri Ramdeobaba College of Engineering and Management, \\ Nagpur, India, Department of Electronics and Communication Engineering \\ ${ }^{3}$ Assistant Professor, Shri Ramdeobaba College of Engineering and Management, \\ Nagpur, India, Department of Electronics and Communication Engineering \\ ${ }^{4}$ Assistant Professor, Shri Ramdeobaba College of Engineering and Management, \\ Nagpur, India, Department of Industrial Engineering
}

\section{ABSTRACT}

In this time of pandemic research trend towards finding research solutions requires data collection and processing capabilities so that human life can be improved by providing faster as well as safer means of results. These results related to impurities that have developed related to human health needs to be processed with the angle of machine learning decade. The means of developing this mechanism when in comes to human health care is the main aim of this research review. The data base to be created is of particles that are subjected to a fluorescence activation mechanism know as laser via a microchannel. This subjection to activation and the reaction of these particles are captured by various means of acquisition. This research article provides an review of flowcytometry principle which helps the researcher to provide a data base acquisition system "FACS". The applications that the FACS system can be utilized are also covered in this review article so that the need of development of such system is justified. The system data and means of acquisition to provide for the data base development is the prime essence of this research article.

KEY WORDS: FLOWCYTOMETRY, FACS, ACQUISITION SYSTEM AND MICROFLUIDICS.

\section{INTRODUCTION}

Technique of bifurcating and providing analysis of physical and chemical characteristics of a fluid particle or liquid is known as Flow cytometry (FCM) as defined in research journal by Picot J et al., Flow cytometry free dictionary website, Beckman Coulter et al. and Givan,

\section{ARTICLE INFORMATION}

*Corresponding Author: agarwalas@rknec.edu

Received 17th Oct 2020 Accepted after revision 29th Dec 2020

Print ISSN: 0974-6455 Online ISSN: 2321-4007 CODEN: BBRCBA

Thomson Reuters ISI Web of Science Clarivate Analytics USA and Crossref Indexed Journal

\section{Clarivate
Analytics}

NAAS Journal Score 2020 (4.31)

A Society of Science and Nature Publication,

Bhopal India 2020. All rights reserved.

Online Contents Available at: http//www.bbrc.in/

Doi: http://dx.doi.org/10.21786/bbrc/13.14/98
Alice L. The principle mechanism of this technique is that a droplet or a complete fluid via a means of microchannel is activated through a fluorescence laser. This activation leads to scattering of light which can be captured by the an acquisition system which can be optical or digital on the whole. Such active marking scheme has been the source of biological processing and result provision related human health care over few decades. The use of such mechanism from the past decades has been in the fields of results pertaining to cell counting, cell sorting, determining cell characteristics and function, detecting microorganisms, biomarker detection, protein engineering detection, diagnosis of health disorders such as blood cancers and many more as reported in Wikipedia. The mechanism covering the "optical means" of data collection can be better understood by the below diagram.

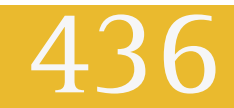


Figur 1: Schematic diagram of a flow cytometer.

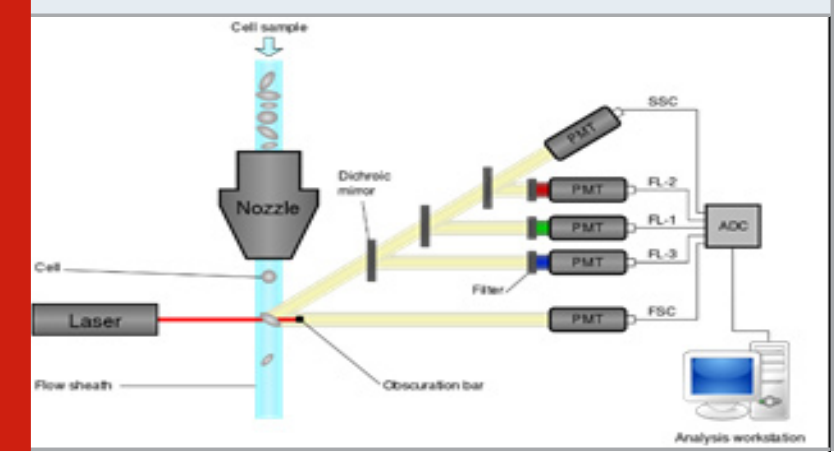

This filed and principle can also be utilized to detect adulteration challenges when we talk about fluid flow analysis performed by Prof. Ankita H. Harkare. The research in the field of adulteration is looking up to microfluidics to provide for a lab on chip solution. The means of developing a data base by a FACS system can also a feasibility, as well as protein based analysis in an controlled environment can provide a great breakthrough in these difficult times of pandemic. On developing such data base will provide for a greater good when machine learning algorithms can provide a tremendous breakthrough in terms of timely and safer means of results provision. Hence the researcher thinks that a through review of FACS system is required.

II. Review: A FACS system has three prime components namely fluidics, optics/ imaging and electronic digitization which are embedded together to provide an complete system. systems: fluidics, optics system, and electronics system.

Figure 2: Schematic diagram of light scattering as in journal by Dean, P.N et al.

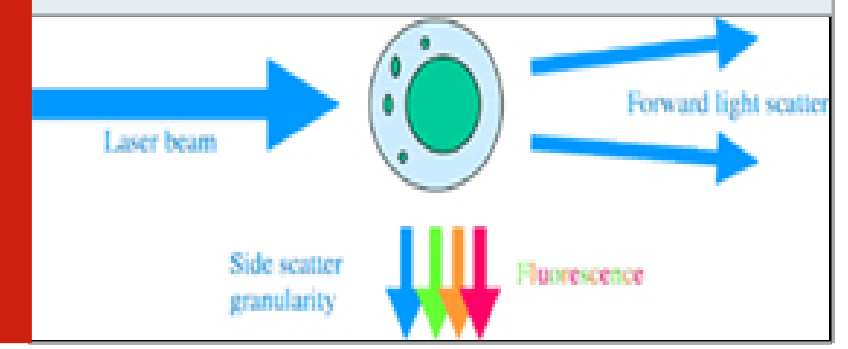

2.1 Fluidics: The need of this backbone system is provide input under test so that they can be subjected to activation via fluorescence. The sample input is processed and injected to the fluidics chamber that is generally a needle based microchannel that can help us control the flow rate. Research articles report that various configurations of micro channels have been utilized that will help control not only the flow rate but also efficient mixing of the sample under test along with stealth fluids. Stealth fluids are added primarily to keep the sample in the center before laser activation. This mixing is done so that the fluid properties can be maintained when we talk about materials with which the microchannel is being developed by Prof. Ankita H. Harkare and Norasyikin Selamat et al. Material analysis also needs to be done when we talk about subjecting this sample to laser beam for activation. This material analysis is required because of light scattering which will happen when we talk about particle sorting and analysis found in the instrumentation journal by biotech, McKinnon et al., Dean, P.N. et al and Enquire bio portal online. The scattering is subject to forward as well as side scattering as shown in figure 2 below and the means by which data acquisition is done is the second requirement of this FACS system.

Table 1. Common Lasers and their Wavelengths

\begin{tabular}{|l|c|}
\hline $\begin{array}{l}\text { LASER } \\
\text { TYPE }\end{array}$ & $\begin{array}{c}\text { WAVELENGTH } \\
\text { (Nanometers) }\end{array}$ \\
\hline Argon Fluoride & 193 \\
\hline Xenon Chloride & 308 and 459 \\
\hline Xenon Fluoride & 353 and 459 \\
\hline Helium Cadmium & $325-442$ \\
\hline Rhodamine 6G & $450-650$ \\
\hline Copper Vapor & 511 and 578 \\
\hline Argon & 488 most used) \\
\hline Frequency doubled & 532 \\
\hline Nd: YAG & 528 (514.5 and \\
\hline Helium Neon & 694,612 and 632.8 \\
\hline Ruby & $630-950$ \\
\hline Laser Diodes & $690-960$ \\
\hline Ti: Sapphire & $720-780$ \\
\hline Alexandrite & 1064 \\
\hline Nd: YAG & $2600-3000$ \\
\hline Hydrogen Fluoride & 1540 \\
\hline Erbium: Glass & $5000-6000$ \\
\hline Carbon Monoxide & 10600 \\
\hline Carbon Dioxide & \\
\hline & 543,3 \\
\hline
\end{tabular}

2.2 Optics System: In flow cytometry recent advancements have overwritten the optical light scattering with digital image acquisition as in Enquire Bio. To avoid the cost factor in developing a system the researcher has restricted the review to optical do maintain the true sense of FASC. The concrete part of the optics is the adducting laser and lens assembly so that the laser scattering and collection can be provided as in journal by Pradeep Kumar et al. The collection lenses and detectors are for providing the light collection means with reference of wavelengths. The amount of energy with subject to activation is also a prime requirement of application which can be understood by fluorescence study in lasers as shown in below table by Robert Aldrich.

2.3 Electronics system: The data provided by the optics system is to be converted from the analog form to its digital format so that the digital data can be utilized and analyzed by the machine learning algorithms clubbed to a dedicated servers to provide enormous fast result processing. 
III. Reported Methodology: The review in terms of methodology is required for advanced in research to provides means of striving financial institutions to sponsor means of fast catering services. The prime need of research is clear to develop a system; but the eventual question under test is how and when. A case study needs to be developed for providing block truncation in terms of facts figures and diagrams. In regards to developing a system that offers its utilization in terms of point of care research highlights the efforts that have been carried out to minimize the size the of flow cytometer which inferentially caters for reduction in cost. The main challenge while reducing the size is that throughput of the detector should not be compromised. Hence laminar flow analysis of the sample have to be carried out to rule out the possibilities of accident or untrue events. Literature reports to avoid such problems chevron shaped groups are to be utilized for microfluidic channel so that the sample fluid remains in center and does not scum to impurity. The size of the channel and its effects have been reported by . Norasyikin Selamat et al. where its simulation is carried out on COMSOL Multiphysics software to justify its importance.

Figure 3: Microchannel in COMSOL.

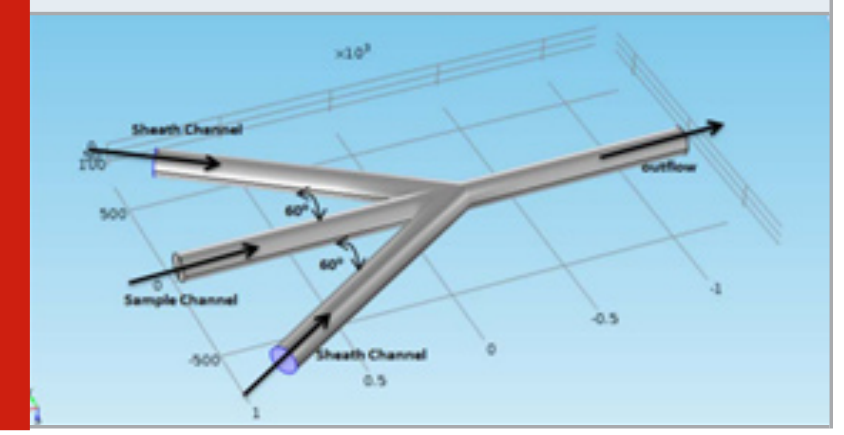

Figure 3: Simulated result for liquid concentration when Qs/Qi is equal to $15 / 10$ at the opening of the focusing channel for three different area, $\mathrm{A}$ where; (a) is for $\mathrm{A}=$ 12500 , (b) is for $A=15000$, and (c) is for $A=17500$.

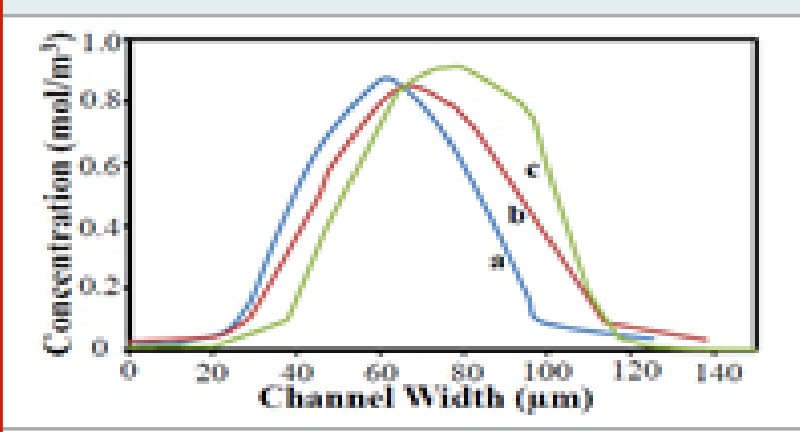

The reporting shows that the channels focusing width is made more focused by maintaining the flow rate ratio $\mathrm{Qs} / \mathrm{Qi}=15 / 10$ in regards to the channel length of $149 \mathrm{~m}$ where Qs is the volumetric flow rate of the side channel as shown in figure 3 and Qi is the volumetric flow rate of the inlet channel. So methodology wise flow control is required and the study requires extensive work in regards to the point of care application for example with respect to pandemic study if biological detection or marking is the application especially when we talk of optics or light scattering when activation takes place. Hence in depth study with respect to COMSOL is the first methodological step that researcher needs to carry out to justify the channel material to be made. The study that provides exact analysis is knows as hydrodynamic analysis. Hydrodynamic stability is the study that provides the researcher with the onset of fluid flow analysis. Theoretically and experimentation wise tools that provide fluid flow analysis require solvers that can provide Reynolds number, Euler equations and NavierStrokes equations which all are available in COMSOL Multiphysics software. Different opening sizes structures have been analyzed based on the concentration levels which are highlighted with respect to below figure 4 .

\section{DISCUSSION AND FUTURE SCOPE}

Preliminary study respect to microchannel and fluid flow analysis show the strong foothold of COMSOL software but these results are still immature and require integration with a laser activation physics that can help us perform robust and optimized system integration efforts to make the system reliable and feasible. Hence researcher proposes the use of Multiphysics in true sense offered by COMSOL and provide a microsystems solution that can help us develop the database for future analysis.

\section{ACKNOWLEDGEMENTS}

The researcher thank the center of microsystem and department of electronics and communication of Shri Ramdeobaba College of Engineering and Management for providing all the resources and timely guidance and support as and when required.

\section{REFERENCES}

Biotech, M. (2018). Flow cytometry instrumentation an overview. Current Protocols in Cytometry, e52. D0I: 10.1002/cpcy.52.

Dean, P.N. and Hoffman, R.A. (2007), Overview of Flow Cytometry Instrumentation. Current Protocols in Cytometry, 39: 1.1.1-1.1.8. DOI:1002/0471142956. cy0101s39

Enquire Bio (2015) online, https://enquirebio.com/flowcytometry

Flow Cytometry (2018-09-18), online, http://www. TheFreeDictionary.com.

Givan, Alice L. (2011). "Flow Cytometry: An Introduction". In Hawley, T.; Hawley, R. (eds.). Flow Cytometry Protocols. Methods in Molecular Biology. 699. Humana Press. pp. 1-29. doi:10.1007/978-1-61737-950-5_1. ISBN 978-1-61737-949-9. PMID 21116976.

McKinnon K. M. (2018). Flow Cytometry: An Overview. Current protocols in immunology, 120, 5.1.1-5.1.11. https://doi.org/10.1002/cpim.40 
Norasyikin Selamat, Muhammad Syafiq Bin Rahim, Abang Annuar Ehsan, "Effect of Microchannel Sizes on 3D Hydrodynamic Focusing of a Microflow Cytometer", IEEE-ICSE2016 Proc. 2016, Kuala Lumpur, Malaysia.

Picot J, Guerin CL, Le Van Kim C, Boulanger CM (March 2012). "Flow cytometry: retrospective, fundamentals and recent instrumentation”. Cytotechnology. 64 (2): 109-30. doi:10.1007/s 10616-011-9415-0. PMC 3279584. PMID 22271369.

Practical Flow Cytometry - Beckman Coulter (02018) online, www.beckman.com

Pradeep Kumar, Mohamed Shuaib B M Saheed, and
Zainal Arif Burhanudin, “ Performance Comparison of One \&Two Quantum Wells Light Emitting Diodes Simulated With COMSOL Multiphysics”, IEEE 2016 Conference, DOI: 10.1109/ICIAS.2016.7824107.

Prof. Ankita H. Harkare, "Analytical Study for Development of Fuel Adulteration Detection System”, Helix Vol. 8(6): 4327- 4333, DOI 10.29042/2018-43274333.

Robert Aldrich Naval Surface Warfare Center- https:// fas.org/man/dod 101/navy/docs/laser/fundamentals. htm

Wikipedia Website, (2020), online, https://en.wikipedia. org/wiki/Flow_cytometry. 